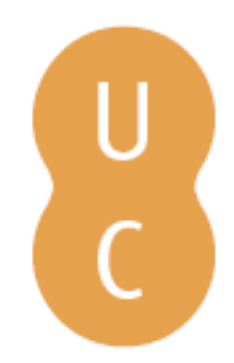

\title{
nommalina
}

\section{El discurso de las mujeres del Agamenón de Séneca}

Autor(es): $\quad$ Arias Abellán, Carmen

Publicado por: Centro de Estudos Clássicos e Humanísticos da Universidade de

URL

persistente: URI:http://hdl.handle.net/10316.2/30167

DOI: $\quad$ DOI:http://dx.doi.org/10.14195/978-989-721-038-9_4

Accessed : $\quad$ 26-Apr-2023 10:26:48

A navegação consulta e descarregamento dos títulos inseridos nas Bibliotecas Digitais UC Digitalis, UC Pombalina e UC Impactum, pressupõem a aceitação plena e sem reservas dos Termos e Condições de Uso destas Bibliotecas Digitais, disponíveis em https://digitalis.uc.pt/pt-pt/termos.

Conforme exposto nos referidos Termos e Condições de Uso, o descarregamento de títulos de acesso restrito requer uma licença válida de autorização devendo o utilizador aceder ao(s) documento(s) a partir de um endereço de IP da instituição detentora da supramencionada licença.

Ao utilizador é apenas permitido o descarregamento para uso pessoal, pelo que o emprego do(s) título(s) descarregado(s) para outro fim, designadamente comercial, carece de autorização do respetivo autor ou editor da obra.

Na medida em que todas as obras da UC Digitalis se encontram protegidas pelo Código do Direito de Autor e Direitos Conexos e demais legislação aplicável, toda a cópia, parcial ou total, deste documento, nos casos em que é legalmente admitida, deverá conter ou fazer-se acompanhar por este aviso.

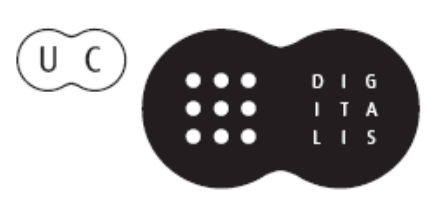




\section{De ayer a hoy}

\section{Influencias clásicas en la literatura}

\section{Aurora López, Andrés Pociña, Maria de Fátima Silva (coords.)}




\title{
El discurso de las mujeres del $A$ Gamenón de Séneca
}

\author{
Carmen Arias Abellán \\ Universidad de Sevilla
}

\begin{abstract}
El análisis del plano del léxico como instrumento de indagación literaria me ha permitido, en un conjunto de trabajos previos sobre el teatro de Séneca, avanzar en cuestiones no afinadas hasta ahora suficientemente por la crítica literaria tradicional. Partiendo de este principio metodológico, la investigación que propongo intenta, como indica su propio título, analizar los personajes femeninos del Agamenón a partir de una "escucha pormenorizada" y de una "indagación exhaustiva" de sus palabras, alcanzando así una caracterización del tratamiento peculiar senecano de dichos personajes y de su "distintividad" respecto a los originales griegos y respecto a las sendas de evolución posteriores a Séneca.
\end{abstract}

Uno de mis ejes de investigación preferentes consiste en la caracterización de los personajes (y de los temas) de las tragedias de Séneca a partir del análisis del vocabulario, o, dicho en otros términos, en el examen del trazado dramático en el nivel de la palabra.

Y es que, según mi criterio, y sobre todo en campos como el de la tragedia, es la escucha atenta del discurso de los personajes, especialmente el que emplean ellos sobre sí mismos, pero también el referido a un personaje concreto por otro personaje, la que nos puede trazar -de modo más contundente y "afinado" que el puro examen literario- el retrato de su singularidad subjetiva, sus tomas de posición respecto al núcleo trágico y respecto a los demás actores.

Esta especificidad subjetiva de los actores sería, además, la que, al partir de las entrañas de los mismos, marcaría la conformación del fondo temático de la tragedia de un modo mucho más determinante que otros factores, comúnmente señalados, pero advenidos "desde fuera", como el destino, la repetición de crímenes y venganzas a lo largo de las generaciones, la fortuna, el poder, etc.

El prisma de la "posición", de las "elecciones" de los datos de la realidad hechas por los personajes, posición y elecciones que obedecerían básicamente a su interioridad subjetiva, va a ser, por tanto, el que ocupe mi mirada en este trabajo.

El estudio de la subjetividad -objeto de la Medicina y de la Psicologíareconoce como parte esencial de la misma la dualidad (pulsional) de "vida" / "muerte" (o de "amor / "odio") ${ }^{1}$, que se conecta respectivamente en el primer

${ }^{1}$ Este principio doctrinal de S. Freud ha sido explicado de un modo muy claro por D. Lagache: "Le pulsioni di vita o eros avviluppano nel medesimo nucleo l'opposizione della conservazione 
caso ("vida" / "amor") con procesos que significan (en el trato que tiene el ser consigo mismo, con la realidad y con los demás) apego, búsqueda del otro, compromiso, etc.; y en el segundo caso ("muerte" / "odio"), con procesos de no vinculación, separación del otro, destrucción, agresividad, etc. ${ }^{2}$.

Contando con esta dualidad (que se manifiesta según cada personalidad con equilibrio de sus dos polos, o con predominio de uno sobre el otro) puede trazarse el dibujo de la especificidad subjetiva de los personajes, plano del que paso a ocuparme centrándome -según lo señalado en el título- en las protagonistas femeninas del Agamenón.

II. El cuadro femenino de esta tragedia lo conforman dos figuras centrales, Casandra y Clitemestra, y dos más colaterales, Electra y la nodriza.

Dadas las limitaciones espaciales y temporales de esta ponencia, haré un recorrido más sucinto por las dos últimas figuras, Electra y la nodriza, deteniéndome en las dos mujeres básicas de la obra, Casandra y Clitemestra.

III. Las actuaciones de Electra y la nodriza se orientan a la salvaguarda de la vida y trazan, por tanto, un dibujo de las mismas ubicado en esta posición vital. Electra, hija de Agamenón y Clitemestra, se ocupa esencialmente de salvar la vida de su hermano Orestes (amenazado por Egisto y Clitemestra, a los que terminará matando vengando así a su padre Agamenón); la nodriza, por su parte, intenta apuntalar la posición vacilante e insegura que, como vamos a ver, caracteriza a su reina (Clitemestra), intentando inclinarla, en todos sus consejos, hacia el vínculo conyugal, hacia la evitación del asesinato de Agamenón y hacia el triunfo, por tanto, del compromiso y de la vida.

IV. Frente a estas dos figuras positivas, Casandra se sitúa en el espacio negativo de la autodestrucción y de la muerte.

Ya a primera vista, llama la atención en este personaje la magnificación del dolor, de la adversidad, cuestión que -además de en sus intervenciones más detenidas, que analizaremos posteriormente- se palpa en la repetición machacona de estos contenidos en el nivel léxico, actualizados sobre todo en el plano sustantivo, de los que recogemos algunos ejemplos a título de ilustración:

aerumnae meae (661)

cladibus meis (662)

nostris malis (663)

di sé e della conservazione della specie... lo scopo consiste nel "legame" (Bindung), ossia nel fatto di satabilire delle unità sempre più vaste e destinate quindi a persistere. Le pulsioni di morte tendono allo sgretolamento dell'insieme, poiché l'ultimo approdo di ogni essere vivente è il ritorno all 'inorganico" (D. Lagache, La Psicanalisi, Milano 1999, 27 [traducción de La Psychanalyse, Presses Universitaires de France, Paris, 1996]).

${ }^{2}$ Procesos que se engarzan, de manera evidente, con la motivación primera de "conservación" / "destrucción" recogida en la nota anterior (cf. P. Bofill - J. L. Tizón, Qué es el Psicoanálisis, Barcelona, Herder, 1994, 90 ss.). 
tantas ruinas (669)

nostra mala (695), etc.

Esta magnificación del sufrimiento -a través de estos lexemas concretosse inserta en la postura mortífera de Casandra, postura que se dibuja más claramente a partir del examen del total de su discurso en la obra, trazándonos tres rasgos esenciales de su "subjetividad": IV.1) su incapacidad para establecer vínculos; IV.2) su abulia o estatismo; IV.3) su relación "gozosa" con la muerte.

IV.1. Aunque quepa ver en ellas cierta búsqueda de privacidad y autonomía (estoica) en su duelo, son esencialmente palabras de absoluta "desvinculación" -y con ello examinamos la primera característica de Casandra- las que les dirige al coro de troyanas cuando éste llora la caída de su ciudad e intenta aliviarla compartiendo con ella el dolor por el fallecimiento de su padre y recordándole que sólo la trampa engañosa del caballo hizo posible la destrucción de Troya (CHO. 664 y 666: Lacrimas lacrimis miscere iunat.../ iunat in medium deflere suos $^{3}$ : "Lágrimas con lágrimas mezclar agrada... agrada llorar en compañía a los suyos"):

CA. Cobibete lacrimas...

... et ipsae uestra lamentabili

lugete gemitu funera: aerumnae meae

socium recusant. Cladibus questus meis

remouete. Nostris ipsa sufficiam malis (659-663)

("Contened las lágrimas... y lamentad vosotras mismas vuestras muertes con gemidos de duelo: mis miserias no admiten alianza. Evitad las quejas por mis infortunios: yo sola me bastaré para mis males").

IV.2. La "inmovilidad" ante su dolorosa historia (proyectada en un anclaje a su pasado y, con ello, en una apatía y aniquilación de su vida actual) constituye la segunda marca de Casandra. Su diálogo con Agamenón, cuando éste intenta atraerla a la realidad presente, muestra nítidamente esta actitud:

AG. Festus dies est. CA. Festus et Troiae fuit (791):

(AG. "Es un día de fiesta". CA. "También fue un día de fiesta para Troya").

AG. Veneremur aras. CA. Cecidit ante aras pater

(AG. "Veneremos los altares". CA. "Mi padre cayó delante del altar").

AG. Ionem precemur pariter. CA. Herceum Ionem? (793)

(AG. “Imploremos juntos a Júpiter”. CA. “¿A Júpiter Herceo?”).

AG. Credis uidere te Ilium? CA. Et Priamum simul (794)

${ }^{3}$ En todos los textos siguientes del Agamenón sigo la edición y traducción de B. Segura Ramos (cf. La tragedia de Agamenón, rey de Micenas, Sevilla, 2008, 26-91). 
(AG. “¿Crees que es Ilión lo que ves?”. CA. "Y a Príamo a un tiempo”).

AG. Hic Troia non est. CA. Vbi Helena est, Troiam puto (795)

(AG. "Aquí no está Troya”. CA. "Donde está Helena, creo que es Troya”), diálogo que tiene un punto culminante en su valoración final positiva de la muerte:

AG. Secura uiue. CA. Mibi mori est securitas (797)

(AG. "Vive sin preocupaciones". CA. "Para mí morir es la ausencia de todas las preocupaciones").

IV.3. El reflejo de este texto, su valoración positiva de la muerte, conforma el último rasgo definitorio de Casandra.

La princesa expresa de nuevo dicho aprecio cuando vaticina el final de Agamenón y el suyo propio ${ }^{4}$ :

CA. ... Iuuat per ipsos ingredi Stygios lacus, iunat uidere Tartari saeuum canem

auidique regna Ditis! Haec hodie ratis

Phlegethontis atri regias animas uehet, uictamque uictricemque (750-754).

("Me gusta caminar por los mismos lagos de la Éstige, me gusta ver el cruel perro del Tártaro y el reino del avaricioso Dite. Hoy esta barca del oscuro Flegetonte transportará ánimas regias, la vencida ${ }^{5}$ y la vencedora”6),

y lo vuelve a repetir cuando, una vez asesinado el rey, va a morir a ella misma por orden de Clitemestra ${ }^{7}$ :

CA. Ne trabite, uestros ipsa praecedam gradus.

Perferre prima nuntium Phrygibus meis

propero: repletum ratibus euersis mare,

captas Mycenas, mille ductorem ducum,

ut paria fata Troicis lueret malis,

perisse dono, feminae stupro, dolo.

Nibil moramur, rapite: quin grates ago:

Iam, iam iuuat uixisse post Troiam, iuuat (1004-1011)

("No me arrastréis, yo misma caminaré delante de vosotros. Me apresuro para ser la primera en llevar las noticias a mis frigios: el mar está repleto de barcos

${ }^{4}$ También anunciará antes de morir el final de Clitemestra y Egisto a manos de Orestes, el hijo de Clitemestra y Agamenón, que vengará con ello a su padre: Veniet et uobis furor (1012).

${ }^{5}$ La propia Casandra.

${ }^{6}$ Agamenón.

${ }^{7}$ Cly. At ista poenas capite persoluet suo / captiua coniunx, regii paelex tori: / trabite ut sequatur coniugem ereptum mibi (1001-1003): "Esa, en cambio, pagará con su cabeza el castigo, la esposa cautiva, mi rival en el real lecho: arrastradla para que acompañe al esposo que me ha arrebatado”. 
hundidos; Micenas, tomada; el comandante de mil jefes ${ }^{8}$-para pagar con un destino idéntico los desastres de Troya- muerto por un presente, por el adulterio de su mujer, por engaño. No me opongo en absoluto, arrastradme; al revés, os doy las gracias: ahora, ahora me agrada haber sobrevivido a Troya, sí, me agrada").

En estos dos textos se percibe nítidamente su posición interior de "gozo por la muerte y el sufrimiento" (la "Lust am Tode" y la "Leidenswollust" de Lefèvre ${ }^{10}$ ): CA.... Iunat per ipsos ingredi Stygios lacus, / iunat uidere Tartari saeuum canem/ auidique regna Ditis. (750-752): "Me gusta caminar por los mismos lagos de la Éstige, me gusta ver el cruel perro del Tártaro y el reino del avaricioso Dite"; CA. Ne trahite: uestros ipsa praecedam gradus.../ Nibil moramur (1004; 1010) "No me arrastréis: yo misma caminaré delante de vosotros... No me opongo en absoluto").

Hay diversas causas objetivas para este gozo: la cancelación definitiva de los problemas que la muerte le traería consigo ${ }^{11}$, el anhelo por ver de nuevo a los suyos y notificarles la destrucción de la flota griega (a su regreso de Troya), la toma de Micenas por un nuevo poder ${ }^{12}$ y la muerte de Agamenón. En todos estos hechos (destrucción de la flota griega, la conquista de Micenas y el final de Agamenón) interpreta Casandra una situación paralela a la sufrida por Troya ("el mar está repleto de barcos hundidos; Micenas, tomada; el comandante de mil jefes ${ }^{13}$ - para pagar con un destino idéntico los desastres de Troya- muerto"..., 1006-1009) y una equiparación final -tema tan euripídeo- de vencedores y vencidos (“... los frigios, vencidos, hemos vencido. Bien está; te levantas, Troya. Has arrastrado al caer junto a ti a Micenas, tu vencedor vuelve la espalda”, 869871), aspectos los dos que constituyen una base importantísima de reparación para ella y su familia (y de ahí su urgencia por notificárselo).

Su desgana de la vida, su deseo de morir se ubica, sin embargo, en el plano, previo a cualquier circunstancia, que es su "esencia interior"; desde esta esencia -llena de gozo por el dolor y la autodestrucción ${ }^{14}$ - Casandra ha elegido -en lugar de la aminoración de las adversidades de la vida, apostando así por dicha vida- el protagonismo de estas adversidades -tan actualizado, según hemos visto ya, en el léxico-, haciendo así una jugada de cesión a la muerte ${ }^{15}$.

${ }^{8}$ Agamenón.

${ }^{9}$ Cf. E. Lefèvre, "Schicksal und Selbstverschuldung in Senecas Agamemnon”, Hermes, 94, 1966, 488.

${ }^{10}$ Cf. E. Lefevre, "Die Schuld des Agamemnon. Das Schicksal des Troja-Siegers in stoicher Sicht”, Hermes, 101, 1973, 89.

${ }^{11} \mathrm{Cf}$. nota 15.

${ }^{12}$ Egisto.

${ }_{13}^{13}$ Agamenón.

${ }^{14}$ Cf. notas 9, 10, y 15.

${ }^{15}$ Ya hemos visto en las notas 9 y 10 que Lefèvre se sitúa en este mismo planteamiento 
Al inicio del estudio de esta figura anunciábamos su ubicación mortífera, su pulsión de muerte, pulsión que se ha visto confirmada a través de sus tres peculiaridades analizadas: aislamiento, desistimiento en la superación de su desgraciado destino y voluntad de dejar la existencia.

V. El personaje de Clitemestra se ubica entre estas dos posiciones de vida (Electra y Nodriza) y de muerte (Casandra).

Son diversos los factores condicionantes de su comportamiento con Agamenón: el más importante quizá, el sacrificio por parte de éste de su hija Ifigenia ${ }^{16}$, pero también su larga ausencia con motivo de la guerra de Troya ${ }^{17}$, sus amoríos ${ }^{18}$, con el último de los cuales, Casandra, regresa, como ya hemos visto, a la patria ${ }^{19}$, las posibles consecuencias de esta relación con la princesa troyana sobre sus hijos y sobre el poder de Micenas ${ }^{20}$, e, incluso, el propio sentimiento de culpa de Clitemestra por su infidelidad a Agamenón mediante su relación con Egisto ${ }^{21}$.

Dichos factores no son, sin embargo, la clave determinante de sus actuaciones, quedando relegados a un segundo plano respecto a su problemática

al destacar en la esencia de Casandra las dos posiciones básicas de "Lust am Tode" ("gozo en la muerte") y de "Leidenswollust" ("gozo total en el sufrimiento"). Esta elección subjetiva de Casandra, de búsqueda de la muerte frente a la vida, señalada abiertamente por ella en el verso 797 -mibi mori est securitas-, encuentra un eco -aunque sacada del ámbito de la subjetividad y transferida a un plano más general y filosófico- en el pensamiento estoico de la mors libera, pensamiento expuesto ampliamente por el coro de troyanas en los versos 589-610 de esta obra.

${ }^{16}$ Cly. ... iugales filiae memini faces / et generum Achillem (158-159): “... me acuerdo de la antorcha nupcial de mi hija, así como de Aquiles, mi yerno” (se refiere Clitemestra a la conducta de Agamenón, que reclama a su esposa y a su hija Ifigenia con la excusa de casar a ésta con Aquiles, cuando lo que hace en realidad es sacrificarla a Artemis para facilitar el curso de la flota griega).

${ }^{17}$ Cly. Decem per annos uidua respiciam uirum? (156).

${ }^{18}$ Cly. amore captae captus (175)"cautivado por el amor de una cautiva", ardore sacrae uirginis iam tum furens (177): "enloquecido ya entonces por la pasión de una virgen sagrada", inter ruentis Graeciae stragem ultimam / sine hoste uictus marcet et Veneri uacat / reparatque amores... (182-184): "En medio de los estragos postreros de Grecia derrumbándose, vencido sin enemigo, se deja embotar y dedica su tiempo a Venus, y encadena amoríos".

${ }^{19} \mathrm{Cly}$. Nunc noum uulnus gerens / amore Phrygiae uatis incensus furit, / et post tropaea Troica ac uersum Ilium / captae maritus remeat et Priami gener (188-191): "Ahora, portando una nueva herida, anda loco, abrasado por el amor de la pitonisa frigia, y tras los trofeos de Troya y la destrucción de Ilión, retorna marido de una cautiva y yerno de Príamo".

${ }^{20}$ Cly. Pigra, quem expectas diem? / Pelopia Phrygiae sceptra dum teneant nurus? / An te morantur uirgines uiduae domi / patrique Orestes similis? Horum te mala / uentura moueant, turbo quis rerum imminet: / quid, misera, cessas? En adest natis tuis / furens nouerca (193-199): "perezosa, ¿qué día aguardas? ¿Hasta que nueras frigias empuñen el cetro de los Pelópidas?... conmuévante los males venideros... he aquí que llega una madrastra enfuercida para tus hijos"

${ }^{21} \mathrm{Cly}$. Licuit pudicos coniugis quondam toros / et sceptra casta uidua tutari fide; / periere mores, ius, decus, pietas, fides, / et qui redire cum perit nescit pudor (110-113): "Otrora me cupo guardar con casta fidelidad el lecho pudoroso de esposa y el cetro privado de dueño. Han muerto las costumbres, la justicia, el decoro, la devoción, la fe y el pudor, que, cuando se pierde, no sabe volver" (cf. igualmente, vv. 116-124 y 134-138). 
fundamental, que no reside en el exterior, sino en su subjetividad, una subjetividad perdida y errática, que actualizan claramente adjetivos y procesos verbales referidos a su persona, de entre los que entresacamos, a título de modelo, los siguientes:

impos sui: "no dueña de sî"(117);

consilii impotens: "incapacitada para una decisión" (126);

animus errat: "su alma anda extraviada" (144), etc.

Es esta "ambivalencia" que habita su "interioridad" la que motiva su indecisión entre el asesinato de Agamenón (muerte) y el vínculo con el compromiso de su matrimonio (vida).

Dicha ambivalencia -de cuya caracterización léxica acabamos de ver unas cuantas muestras- se vierte con toda contundencia en sus siguientes reflexiones ante la nodriza:

\section{CLY....Fluctibus uariis agor}

ut, cum binc profundum uentus, hinc aestus rapit,

incerta dubitat unda cui cedat malo (138-140)

("Me impulsan oleajes encontrados, como, cuando el viento por aquí, por allí la marea arrastra las profundidades, la ola desorientada duda a qué mal ceder")

CLY. Proinde omisi regimen e manibus meis:

quocumque me ira, quo dolor, quo spes feret, hoc ire pergam (141-143)

("En consecuencia, he dejado escapar el timón de mis manos: doquiera me lleve la cólera, doquiera, el dolor, la esperanza, por ahí echaré a caminar”) ${ }^{22}$,

y ésta, la nodriza, capta la raíz psicológica de la situación, advirtiéndole que la resuelva allí, en su psiquismo, domesticando su agresividad y pacificando sus contradicciones:

NVT. ... comprime affectus truces

mentemque tibimet ipsa pacifica tuam (224-225)

("reprime tus terribles sentimientos y pon tu mente en paz contigo misma").

Pero dada la irresoluble vacilación interior de la reina, sus contradicciones podrán ser desanudadas sólo por otra persona, por Egisto, quien, llevado por

${ }^{22}$ Cf. en la misma línea: Cly. mixtus dolori subdidit stimulos timor (133): "mezclado al dolor, el temor le ha prestado a él estímulos"; Cly. ... hinc animum iugo / premit cupido turpis et uinci uetat; / et inter istas mentis obsessae faces, / fessus quidem et deuictus et pessumdatus, / pudor rebellat (134-138): “... de un 
el afán de venganza y por el deseo de poder ${ }^{23}$, hará inclinarse la personalidad oscilante de Clitemestra hacia el lado destructivo ${ }^{24}$, con el asesinato final de Agamenón.

V. Este recorrido por los personajes femeninos del Agamenón desde las claves de su singularidad, para la que he tomado como criterio definidor la organización -deducida de sus propias palabras- de los componentes "amor" / "odio" (o "vida" / "muerte") en su estructura psíquica, nos permite resaltar, en el momento de las conclusiones, la actitud vital de Electra y la nodriza, el abandono en la muerte de Casandra, y la ambivalencia entre estas dos pulsiones de Clitemestra.

${ }^{23}$ Quiere vengar a su padre Tiestes (expulsado de Micenas por su hermano Atreo) y recuperar el reino de Micenas, fines para los que debe impedir a toda costa la posibilidad de que Clitemestra perdone a Agamenón (hijo de Atreo) y la posibilidad, con ello, de que éste siga con vida y manteniendo el poder de Micenas.

${ }^{24}$ No sin las vacilaciones previas que ella -de acuerdo con su perenne duda entre la muerte y la vida- muestra: cf. Cly. Amor iugalis uincit...: / remeemus illuc unde non decuit prius / abire; sed nunc casta repetatur fides, / nam sera numquam est ad bonos mores uia: / quem paenitet peccasse paene est innocens (239-243): "Se sobrepone el amor conyugal...: volvamos allí, de donde antes habría convenido no partir. Mas ahora busquemos de nuevo la casta fidelidad, pues nunca es tarde la vuelta a las buenas costumbres: el que se arrepiente de haber cometido una falta es inocente casi"; Cly. Aegisthe, quid me rursus in praeceps agis / iramque flammis iam residentem incitas? (260-261): "Egisto, ¿por qué me empujas de nuevo al abismo y reavivas con llamas la cólera ya apaciguada?"; Cly. Surgit residuus pristinae mentis pudor; / quid obstrepis? Quid uoce blandiloqua mala / consilia dictas? (288-290): "Se rebela un resto de pudor de mi prístina forma de ser. ¿Por qué me lo afeas? ¿Por qué me dictas malos consejos con tu voz acariciadora?”. 